\title{
Influence of silicon addition on the mechanical properties and corrosion resistance of low-alloy steel
}

\author{
M HEBDA*, H DĘBECKA and J KAZIOR \\ Institute of Materials Engineering, Cracow University of Technology, Warszawska 24, 31-155 Kraków, Poland
}

MS received 17 March 2015; accepted 6 July 2015

\begin{abstract}
The addition of silicon to low-alloy steel allows to modify the materials' microstructure and thus to improve their corrosion resistance and mechanical properties. The influence of adding different amounts of silicon on the properties (density, transverse rupture strength, microhardness and corrosion resistance) and microstructure of low-alloy steel was investigated. Samples were prepared via the mechanical alloying process, which is the most useful method to homogeneously introduce silicon to low-alloy steel. Sintering was performed by using the spark plasma sintering (SPS) technique. After the SPS process, half of each of the obtained samples was heat-treated in a vacuum furnace. The results show that high-density materials were achieved, and a homogeneous and fine microstructure was obtained. The investigated compositions containing $1 \mathrm{wt} \%$ of silicon had better corrosion resistance than samples with $3 \mathrm{wt} \%$ of silicon addition. Furthermore, corrosion resistance as well as the mechanical and plastic properties of the samples with $1 \mathrm{wt} \%$ of silicon can be further improved by applying heat treatment.
\end{abstract}

Keywords. Mechanical alloying; silicon addition; SPS; heat treatment; corrosion resistance.

\section{Introduction}

Spark plasma sintering (SPS) is an effective consolidation technique which is used to obtain fully dense materials (with porosity below 1\%) in a relatively low sintering temperature within a shorter period of time than in the conventional powder metallurgy (PM) process. SPS may be used for the synthesis of various materials (such as metals, ceramics and composites). ${ }^{1-4}$ Increased density along with the desired microstructure of the sinters allow to obtain better mechanical properties of parts produced via powder metallurgy technology. Currently, these methods are used to improve parts made from low-alloy powders, such as Astaloy. ${ }^{5-7}$ Reducing costs with simultaneous improvement of the properties is the ultimate goal of designing new materials. The addition of silicon to low-alloy steel allows to modify the materials' microstructure and thus to improve their corrosion resistance and mechanical properties (e.g., it is possible to obtain a bainitic-austenitic microstructure without precipitations of carbides). At the same time, silicon powder is low cost in comparison to other conventional alloying elements. These two features make competitiveness of PM parts with this addition very high. Unfortunately, silicon has a high affinity for oxygen, which makes its implementation problematic during the sintering process of mixed powders. Moreover, a sintering process of materials with the addition of silicon that is conducted improperly may result in decreased impact strength and elongation, and in significantly reduced wear

\footnotetext{
*Author for correspondence (mhebda@pk.edu.pl)
}

resistance. The most useful process to homogeneously introduce silicon to low-alloy Astaloy $\mathrm{CrL}$ steel is mechanical alloying (MA) ${ }^{8-10}$ Furthermore, the particles of the powders are usually small and hardened after the MA process, and consequently they are difficult to consolidate during the conventional method of compaction. For this reason, SPS is more efficient than conventional methods of powder consolidation after the MA process. ${ }^{11-14}$

The aim of the present work was to investigate the influence of adding different amounts of silicon on the properties (density, transverse rupture strength, microhardness and corrosion resistance) and microstructure of Astaloy $\mathrm{CrL}$ sinters produced by mechanical alloying followed by the SPS process. The influence of applied heat treatment on the obtained microstructure and properties of the materials was investigated.

\section{Materials and methods}

The specimens were prepared by mechanical alloying of Astaloy CrL powders (water-atomized iron powder with the addition of $1.5 \mathrm{wt} \%$ of $\mathrm{Cr}$ and $0.2 \mathrm{wt} \%$ of $\mathrm{Mo}$, manufactured and supplied by Hoganas AB Sweden) with $1 \mathrm{wt} \%$ of stearic acid (supplied by Sigma-Aldrich) and 1 or $3 \mathrm{wt} \%$ of silicon (supplied by Sigma-Aldrich). Stearic acid $\left(\mathrm{CH}_{3}\left(\mathrm{CH}_{2}\right)_{16} \mathrm{COOH}\right)$ was added to the powder mixture as the agent controlling the mechanical alloying process and, in particular, to avoid powder particle agglomeration. The total mass of the alloyed mixture was about $80 \mathrm{~g}$. For MA, a highly energetic planetary mono-ball mill (Fritsch Pulverisette 6 model) was used. The process was carried out in 
a tempered steel container ( $500 \mathrm{ml}$ volume) equipped with grinding balls (AISI 52100 ; $\varnothing 10 \mathrm{~mm}$ ) under a vacuum atmosphere. The ratio of powder mass to ball mass was at a level of $1: 10$. The time of milling was 3 min with a 30 min intermission period; number of cycles-100, and rotary speed500 rot $\mathrm{min}^{-1}$. Carbon (0.4 wt\%, Timrex F10 PM Special Graphite supplied by TIMCAL) was added to the mixture powders directly after the MA process. Powders with added carbon were mixed using Turbula equipment for $24 \mathrm{~h}$. Next, all samples were consolidated using the SPS (in the SPS HP 5 device produced by the FC company). During the process, $50 \mathrm{MPa}$ pressure was applied and argon was used as a protective atmosphere. The process was carried out using $40 \mathrm{~ms}$ long power impulses divided by $10 \mathrm{~ms}$ breaks. Samples were heated at $2^{\circ} \mathrm{C} \mathrm{s}^{-1}$ to an isothermal sintering temperature of $900^{\circ} \mathrm{C}$, held at $900^{\circ} \mathrm{C}$ for $10 \mathrm{~min}$ and then cooled at $5^{\circ} \mathrm{C} \mathrm{s}^{-1}$ to $450^{\circ} \mathrm{C}$. Annealing lasted $9 \mathrm{~min}$ and the samples were cooled to ambient temperature at a rate of $4^{\circ} \mathrm{C} \mathrm{s}^{-1}$. The overall time of sample consolidation in the SPS device was $27 \mathrm{~min}$. After the SPS process, cylindrical samples with a diameter of $30 \mathrm{~mm}$ and a height of $5 \mathrm{~mm}$ were obtained. Next, they were cut into halves using a diamond disk in the Accutom-2 cutting machine. One half of each of the consolidated samples was heat-treated in a vacuum furnace (Seco Warwick). Samples were heated at $10^{\circ} \mathrm{C} \mathrm{s}^{-1}$ to an isothermal sintering temperature of $1200^{\circ} \mathrm{C}$, held at that temperature for $60 \mathrm{~min}$ and then cooled at $100^{\circ} \mathrm{C} \mathrm{s}^{-1}$ to $350^{\circ} \mathrm{C}$. Annealing lasted 180 $\min$. Then the samples were cooled in the furnace. Table 1 shows a summary of the samples used for the investigation.

Density of the specimens was measured by using the water displacement method following the ASTM B328-96 standard test method. Cuboidal $5 \mathrm{~mm} \times 6 \mathrm{~mm} \times 20 \mathrm{~mm}$ samples were used for the transverse rupture strength (TRS) test (according to ASTM B528 standards). Measurements were carried out on MTS Criterion Model 43 equipment. Microhardness (HV0.025) of the samples after the SPS process as well as samples after annealing in a vacuum furnace was determined using the microhardness model Nexus 423A equipped with a Nexus Inv-1 set (at least ten measurements were carried out). The polarization test (using a potentiostat-galvanostat 0531 produced by the Atlas company) was carried out to determine corrosion behaviour. Measurements were conducted in a three-electrode cell consisting of the specimen, a saturated calomel electrode and a platinum electrode as the working reference and counter electrode, respectively. The electrochemical experiments were performed in $0.1 \mathrm{M}$ sodium chloride solutions under atmospheric pressure and in room temperature $\left(21^{\circ} \mathrm{C}\right)$. Tests were conducted after $20 \mathrm{~min}$ of exposure of the sintered samples to ensure stabilization of the corrosion potential $\left(E_{\text {corr }}\right)$. The exposed area of the working electrode was $7 \mathrm{~mm}^{2}$. Polarization curves were recorded between -0.85 and $0 \mathrm{~V}$ at a scan rate of $1 \mathrm{mV} \mathrm{s}^{-1}$. Also, homogeneity and chemical composition of the specimens were checked using a Jeol JSM-5510LV scanning electron microscope (SEM) with an energy-dispersive spectrometer (EDS), IXRF Systems Model 500 Digital Processing.

\section{Results and discussion}

The process of mechanical alloying and the SPS provided homogeneous microstructures with evenly distributed silicon particles. The concentrations of chemical elements for Astaloy CrL powder with the addition of $3 \mathrm{wt} \%$ of $\mathrm{Si}$ and $0.4 \mathrm{wt} \%$ of $\mathrm{C}$ are presented in figure 1 . Similar results were obtained regardless of the amount of silicon that was introduced to the mixtures. That is why only one map is presented in this paper. The results of mapping conducted for the sample marked as $3 \mathrm{Si}$ confirm that the silicon was successfully distributed in the whole volume of the material.

Densities of the samples were measured in order to establish if the consolidation process was carried out successfully. Table 1 shows the obtained results. These results show very high and similar densities for all of the investigated compositions. Therefore, any differences in the measured mechanical properties and/or corrosion resistance can be caused only by structural changes of the material.

Microstructure observations were conducted for samples produced using the SPS and for samples that were heattreated in a vacuum furnace. The microstructures of samples in unetched state show a small share of porosity (rather fine, regularly shaped and evenly distributed). This effect did not depend on the amount of introduced silicon nor on the heat treatment that was applied. These results are in accordance with the outcomes of the density measurements.

Figures 2 and 3 show the results of changes of force and displacement for all of the investigated samples recorded during the TRS test.

The increase in silicon content (from 1 to $3 \mathrm{wt} \%$ ) caused a decrease in the strength and plastic properties of the sinters. The lower force was sufficient to destroy the sinters. Less deformation of samples before they ruptured was also

Table 1. Chemical composition densities, and results of transverse rupture strength for Astaloy CrL processed by SPS with the addition of 1 or $3 \mathrm{wt} \%$ of silicon before and after heat treatment.

\begin{tabular}{lccccccc}
\hline $\begin{array}{l}\text { Notation of } \\
\text { samples }\end{array}$ & \multicolumn{2}{c}{ Chemical composition (wt\%) } & & $\begin{array}{c}\text { Heat } \\
\text { treatment }\end{array}$ & $\begin{array}{c}\text { Density } \\
(\%)\end{array}$ & $\begin{array}{c}\text { Transverse rupture } \\
\text { strength (MPa) }\end{array}$ \\
\cline { 2 - 4 } & Astaloy CrL & $\mathrm{Si}$ & $\mathrm{C}$ & & & &
\end{tabular}




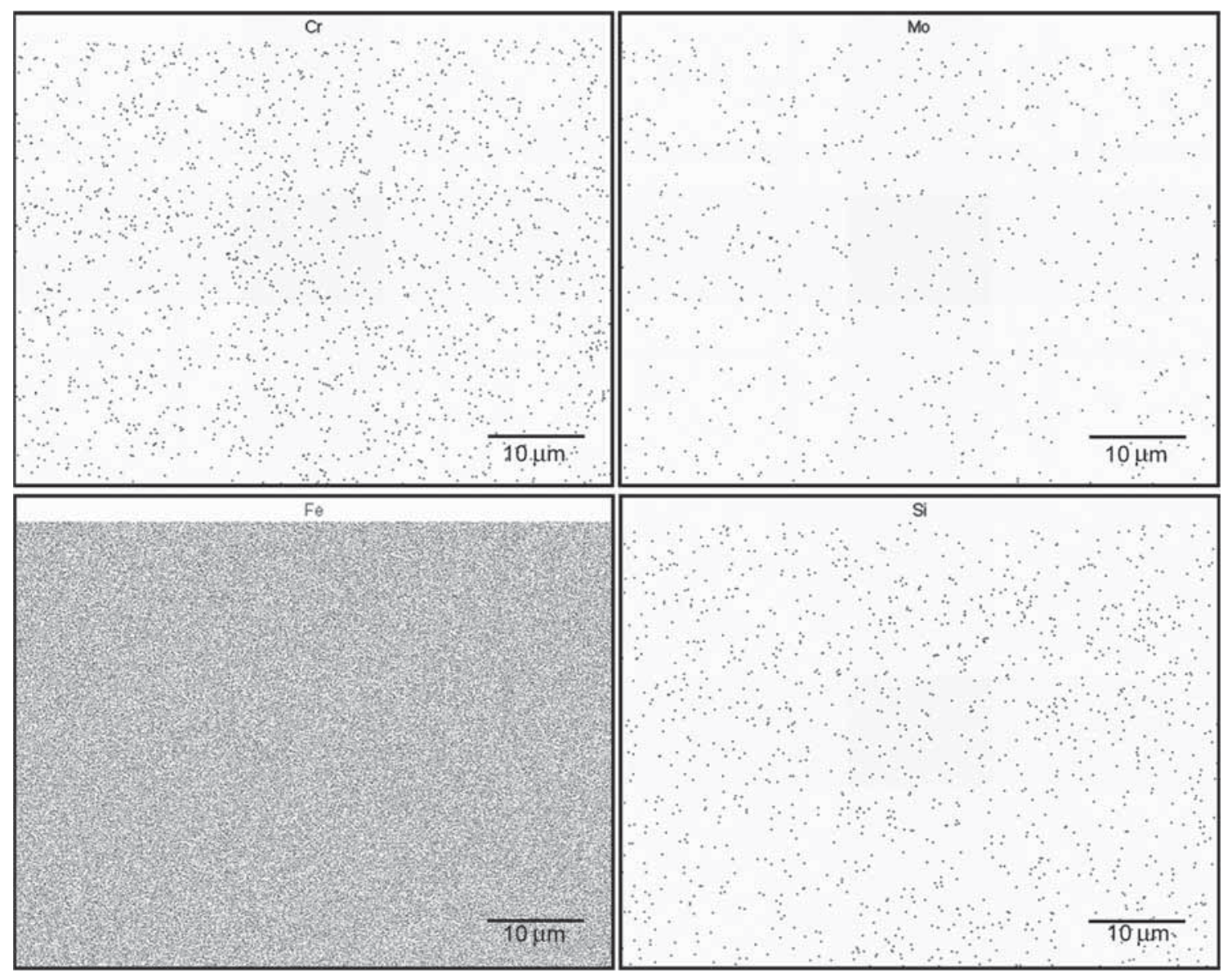

Figure 1. Maps of the spread of chemical elements in a Astaloy CrL processed by SPS with the addition of 3 wt $\%$ of $\mathrm{Si}$ and $0.4 \mathrm{wt} \%$ of $\mathrm{C}$.

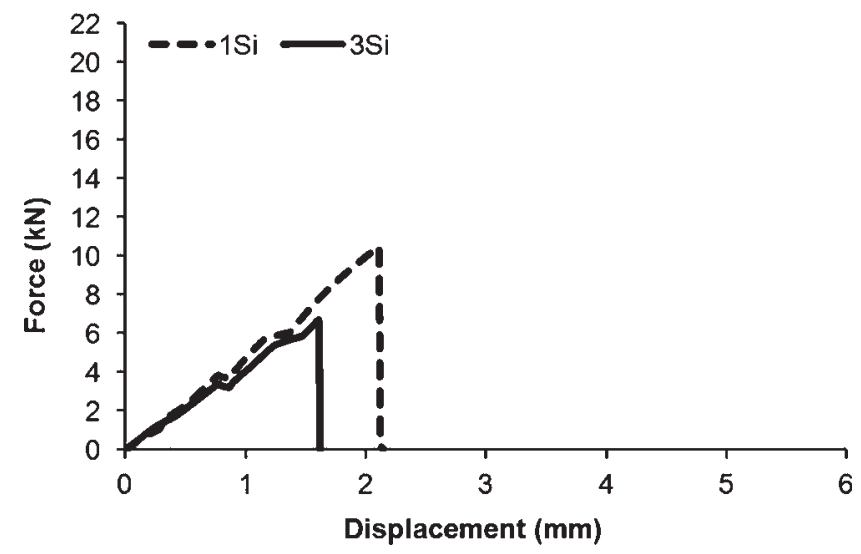

Figure 2. Results of the TRS test for Astaloy CrL processed by SPS with the addition of 1 or $3 \mathrm{wt} \%$ of silicon before heat treatment.

recorded. The conducted heat treatment also did not change this dependency.

Applying heat treatment allowed us to obtain much better mechanical properties of the sintered materials (changes in the sinters' microstructure indicated this). These effects were not dependent on the amount of silicon introduced into

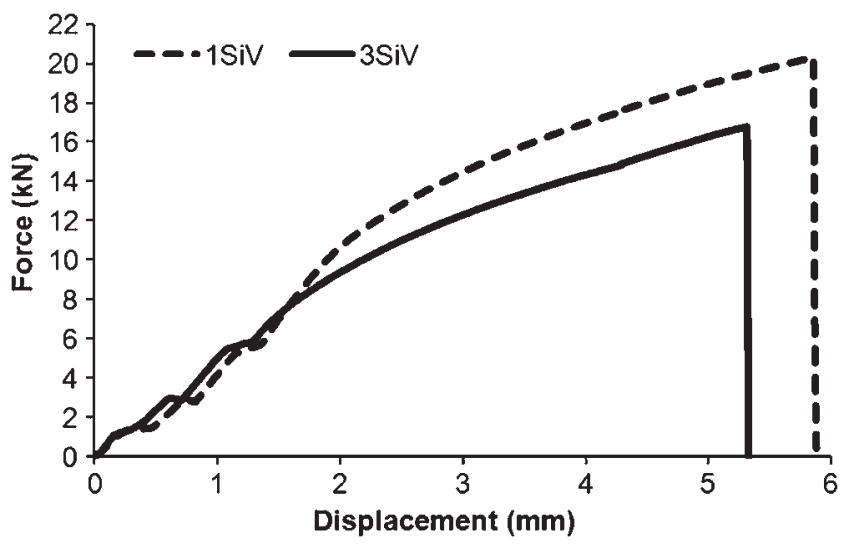

Figure 3. Results of the TRS test for Astaloy CrL processed by SPS with the addition of 1 or $3 \mathrm{wt} \%$ of silicon after heat treatment.

Astaloy CrL. A major improvement was recorded for samples with the addition of $1 \mathrm{wt} \%$ of Si powder (an approximately two-fold increase in the force required to fracture the samples and a nearly three-fold increase in ductility in comparison with samples before heat treatment, figures 2 and 3). 
Based on the data obtained during the measurements (maximum force before rupture of the samples and geometric dimensions of the samples), the transverse rupture strength was calculated for all of the investigated compositions. The obtained results are presented in table 1 .

It was found that the conducted heat treatment of samples with Si powder addition allowed us to obtain a ca. two-fold increase in transverse rupture strength. The topography of the fracture was examined for two samples, for which the value of TRS was the lowest (figure 4a, Astaloy $\mathrm{CrL}$ with $3 \mathrm{wt} \%$ of $\mathrm{Si}$, marked as $3 \mathrm{Si}$ ) and the highest (figure $4 \mathrm{~b}$, Astaloy $\mathrm{CrL}$ with $3 \mathrm{wt} \%$ of Si after heat treatment, marked as $3 \mathrm{SiV}$ ).

From this observation it was established that for sample 3Si (containing Astaloy CrL with the addition of $3 \mathrm{wt} \%$ of $\mathrm{Si}$ and $0.4 \mathrm{wt} \%$ of $\mathrm{C}$, without heat treatment in the vacuum furnace), whose value of the TRS was the lowest (TRS = $1392 \mathrm{MPa}$, table 1), intergranular fracture could be observed (figure 4a). In figure $4 a$, areas in the shape of polygons corresponding to the shapes of the grains may be observed; these are characteristic of intergranular fracture facets.

On the other hand, the fracture of sintered Astaloy CrL with the addition of $3 \mathrm{wt} \%$ of $\mathrm{Si}$ and $0.4 \mathrm{wt} \%$ of $\mathrm{C}$ after heat treatment (figure $4 \mathrm{~b}$ ) was transcrystallic. A transcrystallic fracture occurs when the surface energy in the cleavage planes is larger than the surface energy of the grain boundaries. One of the reasons for a decrease in coherence of the material on the grain boundaries below the level of coherence in the cleats is the existence of voids along those grain boundaries. At the turn of the surface, semi-cleavage facets and plastic dimples (rather shallow and small in size) can be observed. The presence of a region with plastic dimples indicates more ductile failure.

For all of the investigated samples, the microstructure observations revealed that the material consisted of two phases. These microstructures were very fine and uniformly distributed throughout the whole area of the sinters. After heat treatment of the samples with the addition of silicon, the sintered microstructures became more homogeneous (no black precipitations in the structure) as a result of the diffusion process. This observation was confirmed by the high plastic properties registered during the TRS analysis and by the increase in corrosion resistance.

The most significant changes in both the microstructures and mechanical properties were obtained for samples after heat treatment. Therefore, the microstructures were observed with the use of the SEM for these samples (figure $4 \mathrm{c}$ and d).

After analysing figure $4 \mathrm{c}$ and $\mathrm{d}$, it is clear that samples with silicon addition have similar microstructures regardless of the amount of silicon that was added. It is worth mentioning, though, that the dark precipitations in sinters containing $3 \mathrm{wt} \%$ of Si (sample 3SiV) are finer and more evenly spread out. Also, in sample $3 \mathrm{SiV}$ the perlite structure covers a larger area.
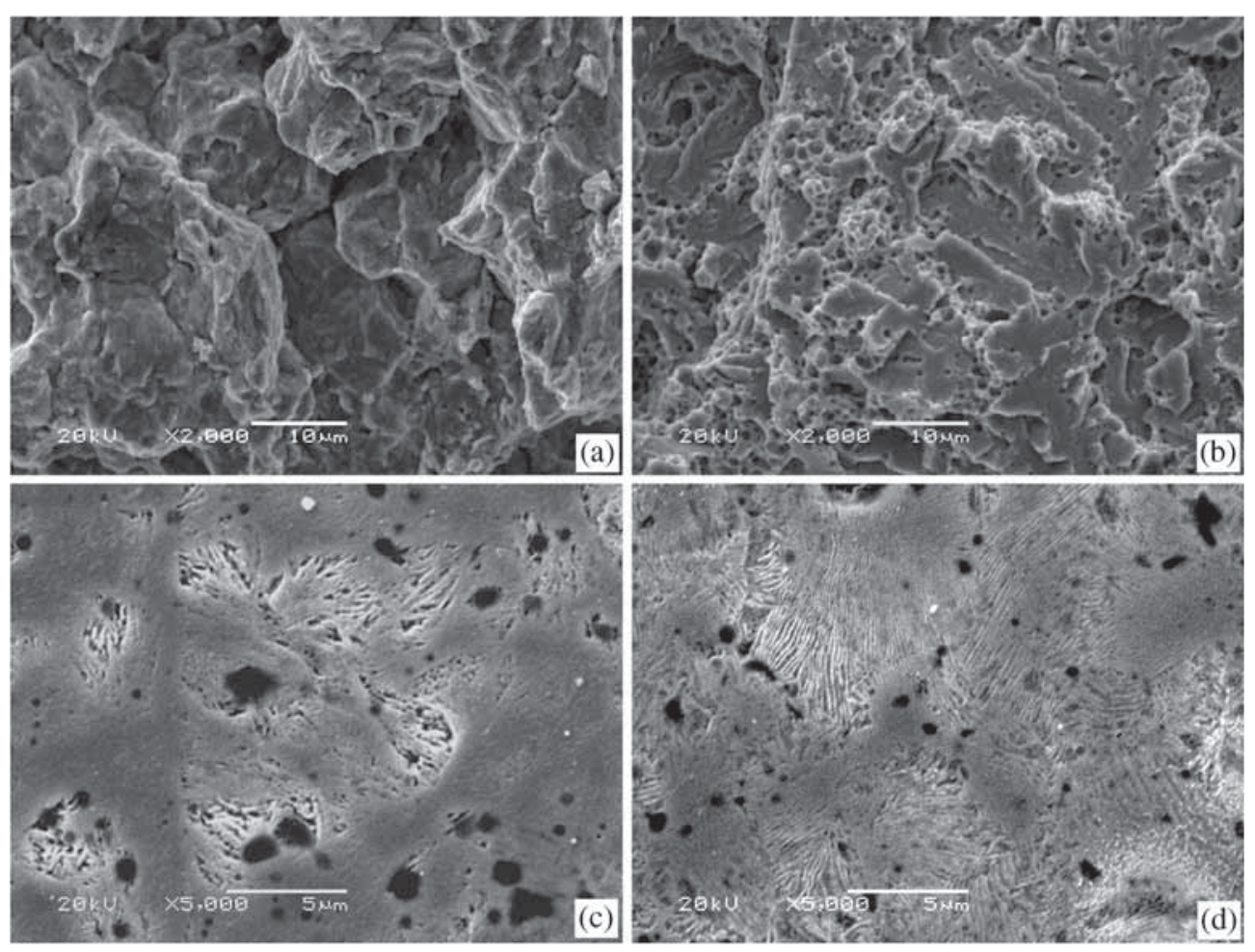

Figure 4. Fracture microstructures of: (a) Astaloy $\mathrm{CrL}$ with 3 wt $\%$ of $\mathrm{Si}$, (b) Astaloy CrL with 3 wt $\%$ of $\mathrm{Si}$ after heat treatment. Microstructures of Astaloy CrL processed by SPS with the addition of: (c) $1 \mathrm{wt} \%$ of silicon followed by heat treatment and (d) $3 \mathrm{wt} \%$ of silicon followed by heat treatment. 


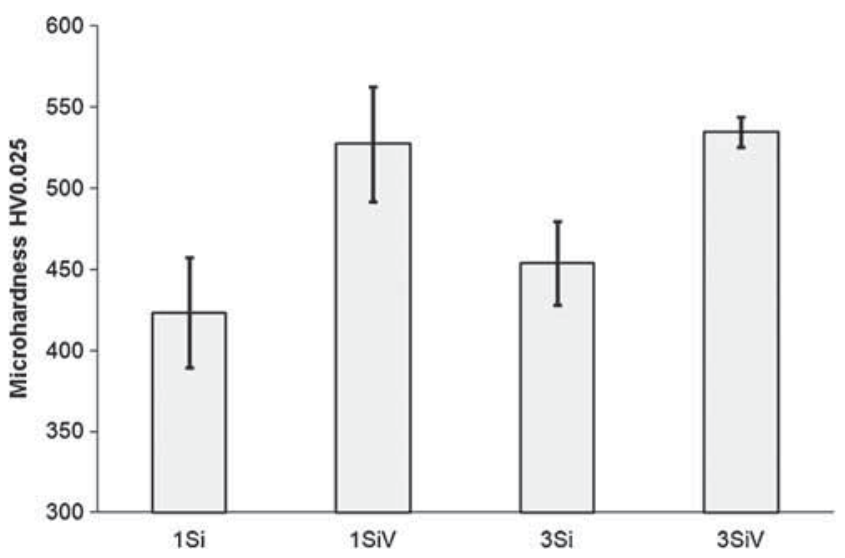

Figure 5. Results of the microhardness test for Astaloy CrL processed by SPS with the addition of 1 or $3 \mathrm{wt} \%$ of silicon before and after heat treatment.

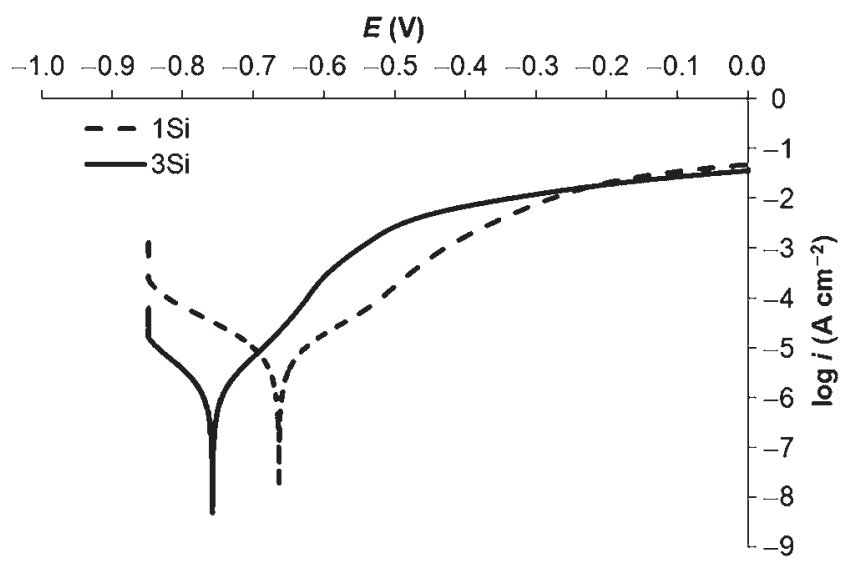

Figure 6. Polarization curves of Astaloy CrL processed by SPS with the addition of 1 or $3 \mathrm{wt} \%$ of silicon before heat treatment.

The manufacturer of the Astaloy CrL materials states that the sintered parts, after pressing in a die and conventional sintering in a furnace, have an expected microhardness value of about $270 \mathrm{HV}$. Each of the samples with the addition of silicon obtained using SPS achieved a microhardness that was higher than $300 \mathrm{HV}$ (figure 5). This effect is the result of having introduced the silicon addition. Moreover, the increase in the silicon content increased the material's microhardness.

A simple relation can be observed for samples with the addition of silicon-heat treatment in a vacuum furnace caused an increase in microhardness (as well as a density and TRS increase) of the samples. The largest increase was recorded for samples containing $1 \mathrm{wt} \%$ of the silicon addition in the elemental form.

The polarization curves (corrosion current density (log $i$ ) depending on electrode potential $(E)$ ) were determined during the corrosion test. Figures 6 and 7 present the obtained results.

Based on the obtained results, a corrosion potential increase after applying the heat treatment process was observed for samples containing $1 \mathrm{wt} \%$ addition of silicon

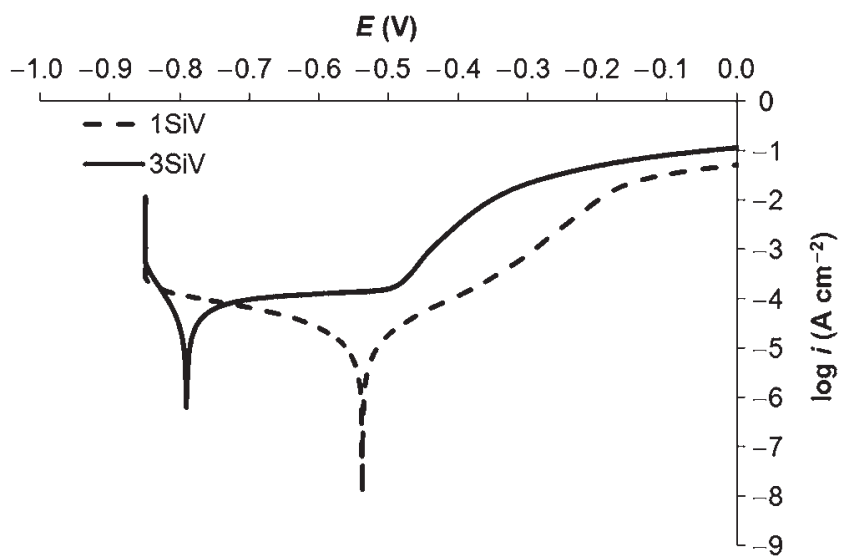

Figure 7. Polarization curves of Astaloy CrL processed by SPS with the addition of 1 or $3 \mathrm{wt} \%$ of silicon after heat treatment.

Table 2. Values of corrosion potential of Astaloy CrL processed by SPS with the addition of 1 or 3 wt $\%$ of silicon before and after heat treatment.

\begin{tabular}{lcc}
\hline Si & Heat treatment & Corrosion potential, $E_{\text {corr }}(\mathrm{V})$ \\
\hline \multirow{2}{*}{$\mathrm{wt} \%$} & No & -0.664 \\
& Yes & -0.537 \\
$3 \mathrm{wt} \%$ & No & -0.758 \\
& Yes & -0.790 \\
\hline
\end{tabular}

(table 2). On the other hand, the corrosion potential of the samples with addition of $3 \mathrm{wt} \%$ of $\mathrm{Si}$ is not dependent on the heat treatment applied (table 2). These results may result from the formation of the silicon-containing phase which had low corrosion resistance. This phase may be formed during the heat treatment process.

\section{Conclusions}

The mechanical alloying process allowed us to effectively and homogeneously introduce silicon to Astaloy CrL powder. Use of the SPS process allowed to obtain sinters from low-alloy steel with silicon addition with a density higher than $95 \%$. The heat treatment that followed the SPS process resulted in a significant increase in the mechanical and plastic properties of samples with the addition of $1 \mathrm{wt} \%$ of silicon. The investigated compositions containing $1 \mathrm{wt} \%$ of silicon had better corrosion resistance than samples with $3 \mathrm{wt} \%$ of silicon addition. Furthermore, corrosion resistance of the samples with $1 \mathrm{wt} \%$ of silicon can be further improved by applying heat treatment. All of the obtained materials were characterized by a fine microstructure.

\section{Acknowledgements}

This work was supported by the Polish Ministry of Science and Higher Education within Grant no. NN508393237. 


\section{References}

1. Borkar T and Banerjee R 2014 Mater. Sci. Eng. A 618176

2. Libardi S, Leoni M, Facchini L, D'Incau M, Scardi P and Molinari A 2007 Mater. Sci. Eng. A 445-446 244

3. Mandal M, Singh D, Gouthama Murty B S, Sangal S and Mondal K 2014 Bull. Mater. Sci. 37743

4. Cipolloni G, Pellizzari M, Molinari A, Hebda M and Zadra M 2015 Powder Technol. 27551

5. Ciripova L, Hryha E, Dudrova E and Vyrostkova A 2012 Mater. Des. 35619

6. Dizdar S, Grosser H and Engström U 2011 Wear 27317

7. Ciaś A and Sułowski M 2009 Arch. Metall. Mater. 541093
8. Azadbeh M and Ahmadi N P 2009 Curr. Appl. Phys. 9 777

9. Hebda M, Gadek S and Kazior J 2012 Arch. Metal. Mater. 57 733

10. Hebda M, Gảdek S, Miernik K and Kazior J 2014 Adv. Powder Technol. 25543

11. He Q, Jia C and Meng J 2006 Mater. Sci. Eng. A 428314

12. Locci AM, Orrù R, Cao G and Munir ZA 2006 Mater. Sci. Eng. A 43423

13. Hebda M, Gảdek S, Skałoń M and Kazior J 2013 J. Therm. Anal. Calorim. 113395

14. Yi J, Xue W J, Xie Z P, Liu W, Cheng L X, Chen J, Cheng H and Gao Y X 2013 Mater. Sci. Eng. A 56913 